\title{
Type and design of cabin units for luxury cruise ships
}

\author{
Fan ShiDa, Gu XiaoBo
}

\begin{abstract}
Cabin is the largest functional module on the cruise ship, and it is also one of the cabin types closest to the life of tourists. At present, cruise tickets are usually divided according to the level of the cabin, according to the level from high to low can be divided into suites, balcony room, sea view room and cabin room, each type of guest rooms will be equipped with a certain number of barrier-free rooms. As a place for passengers to rest, the quality of the cabin will directly affect tourists' evaluation of the whole cruise ship, so the cabin design is very important. The type of cabin depends on where it is on the cruise ship. The design of the passenger cabin of the cruise ship should start from the needs of tourists, according to the reasonable arrangement of ergonomic function composition, clever arrangement of family equipment in the limited space, to create a safe and comfortable accommodation environment for tourists.
\end{abstract}

Index Terms - Cruise, Cabin,Unit Design.

\section{BEHAVIORAL NEEDS OF CABIN UNITS}

Cabin units meet the most basic needs of visitors. The ship is used only as a means of transport, the cabin is furnished with a single bed, up and down a number of beds, just like the sleeping space on the train; Nowadays, the function of luxury cruise ship is no longer just transportation. Its main leisure and vacation function requires that the cabin can provide more demands for tourists and reach higher design standards in terms of function and comfort. According to the hierarchy of use requirements, it can be divided into two categories:

\section{(1) Basic needs}

Basic needs are behavioral needs that all cabins must meet: sleep, toilet, toilet, writing, grooming, storage and rest.

\section{(2) Expanding demand}

The expansion demand is the higher level demand of tourists: viewing, wine tasting, tea drinking, dining, watching $\mathrm{TV}$, listening to music and receiving guests, etc. The above are also the key factors for the diversity and heterogeneity of cabin design.

\section{CONFIGURATION AND PROPORTION OF CABIN TYPES}

The configuration of cabin type is an important part of the preliminary work and design stage of luxury cruise ships and also one of the main bases of cabin design.

Fan Shida, JiangSu University of Science and Technology,Ship and Ocean Engineering institute, JiangSu ZhenJiang +86-17368088820,

Gu Xiaobo, JiangSu University of Science and Technology,Ship and Ocean Engineering institute, JiangSu ZhenJiang +86-13305280246
Because the cruise cabin is relatively stable in a certain period of time, it is seldom rebuilt or rebuilt. Therefore, the configuration of the cabin type should be scientific and based on the principle of ship type requirements and favorable ship characteristics. And there should be flexibility to adapt to the market and tourist demand may change.

The luxurious cruise ship on current market sets 4 kinds of permanent cabin: suite room, oceanview room, balcony room and flatlet, and include a certain number of barrier-free room. Sometimes, another 1-2 types of cabins will be added separately to expand the reception objects, such as adding single rooms and connecting cabins.

Through the configuration of cabin type can realize pair of passenger source screen, in individual luxurious cruises, have balcony room and flatlet only, do not install any inside cabin room, face the client that has economic actual strength only. Most luxury cruise ships feature a wide variety of cabin types and complete specifications.

In the luxury cruise ship, the double room cabin is the main room of the luxury cruise ship, accounting for more than $80 \%$ of the total number of cabins, so the double room cabin unit is often called the standard cabin unit. Generally speaking, room of suite room, oceanview room, balcony room belongs to double cabin unit, some rooms also can pass the way that adds bed or change sofa to be a bed to accommodate more person, but basic room still belongs to type of standard cabin.

Suite unit is an important aspect to show the quality of luxury cruise ships. Its interior furnishings and equipment are better than ordinary cabins. The setting of flatlet is commonly "because of scene make measure", in order to assure good landscape to face, flatlet can be built among among cruise ship one layer or hold two, the position is in normally prow, stern of the boat or the unusual space of shipshape, some flatlet even have individual entrance and exit. In recent years, the United States and European cruise lines have emerged single suites, double suites, and even more suite luxury cabin, to adapt to business, family and long-term living needs of tourists.

A single cabin is a single bed room, providing guests with a good privacy, from the two people sharing some of the inconvenience. In the past, cruise ships rarely had this kind of room, but with the continuous development of cruise industry, more new concepts and designs keep emerging. Now, many cruise companies have also set up a certain proportion of single cabins. This kind of room usually has a small area, but it is well-equipped, compact and economical.

Take the following cabin configuration of royal Caribbean cruises' 138,000 ton mariner of the seas as an example: 
Table 1. Sea mariner's cabin configuration

\begin{tabular}{|c|c|c|c|c|}
\hline Cabin type & Cabin name & $\begin{array}{l}\text { Cabin } \\
\text { number }\end{array}$ & $\begin{array}{l}\text { Deck } \\
\text { distributio } \\
\mathrm{n}\end{array}$ & $\begin{array}{l}\text { Cabin } \\
\text { area } \\
\left(\mathrm{m}^{2}\right)\end{array}$ \\
\hline \multirow{5}{*}{ Suite } & Royal suite & 1 & D10 & 110 \\
\hline & $\begin{array}{l}\text { Master } \\
\text { flatlet }\end{array}$ & 10 & D10 & 47 \\
\hline & Family suite & 4 & D8, D9 & 57 \\
\hline & Grand suite & 23 & D10 & 35 \\
\hline & Junior suite & 72 & D6 D10 & 26 \\
\hline \multirow{2}{*}{$\begin{array}{l}\text { The } \\
\text { balcony } \\
\text { room }\end{array}$} & $\begin{array}{l}\text { Superior } \\
\text { Balcony }\end{array}$ & 370 & D6 D10 & 17 \\
\hline & $\begin{array}{l}\text { Delude } \\
\text { Balcony } \\
\end{array}$ & 268 & D6 D10 & 17 \\
\hline \multirow{3}{*}{ Oceanview } & $\begin{array}{l}\text { Family } \\
\text { Oceanview }\end{array}$ & 8 & $\begin{array}{l}\text { D6, D8, } \\
\text { D9 }\end{array}$ & 30 \\
\hline & $\begin{array}{l}\text { Lager } \\
\text { Oceanview }\end{array}$ & 16 & D6 D9 & 20 \\
\hline & Oceanview & 153 & $\begin{array}{l}\text { D2 , } \\
\text { D6 D9 }\end{array}$ & 17 \\
\hline \multirow{2}{*}{$\begin{array}{l}\text { Interior } \\
\text { room }\end{array}$} & $\begin{array}{l}\text { Promenade } \\
\text { view }\end{array}$ & 137 & $\begin{array}{ll}\text { D6 , } & \text { D7 } \\
\text {, D8 } & \end{array}$ & 16 \\
\hline & $\begin{array}{l}\text { Interiort } \\
\text { room }\end{array}$ & 469 & D6 D10 & 15 \\
\hline \multirow{5}{*}{$\begin{array}{l}\text { Barrier-free } \\
\text { room }\end{array}$} & $\begin{array}{l}\text { Barrier-free } \\
\text { suite }\end{array}$ & 2 & D10 & 28 \\
\hline & $\begin{array}{l}\text { Barrier-free } \\
\text { Balcony }\end{array}$ & 8 & D6, D7 & 25 \\
\hline & $\begin{array}{l}\text { Barrier-free } \\
\text { Oceanview }\end{array}$ & 6 & D2 & 23 \\
\hline & $\begin{array}{l}\text { Barrier-free } \\
\text { Promenade } \\
\text { view } \\
\end{array}$ & 1 & D7 & 23 \\
\hline & $\begin{array}{l}\text { Barrier-free } \\
\text { interior }\end{array}$ & 9 & D9, D10 & 23 \\
\hline All & & 1557 & & \\
\hline
\end{tabular}

\section{TYPE AND DESIGN OF CABIN UNITS TYPE AND DESIGN OF} CABIN UNITS

\section{A. Interior cabin}

Because of the interior of the ship, most of the inner cabin has no external Windows or portholes, so the space is closed and dark. Therefore, the inner cabin is the cheapest cabin on the cruise ship. With the gradual improvement of tourists' requirements for comfort, the hull that can be built can be continuously expanded. Nowadays, cruise ships often set tall atriums in the middle of the hull, so that the inner cabin can also be set with Windows opening to the atrium, greatly improving the deficiency of complete closure of the inner cabin.

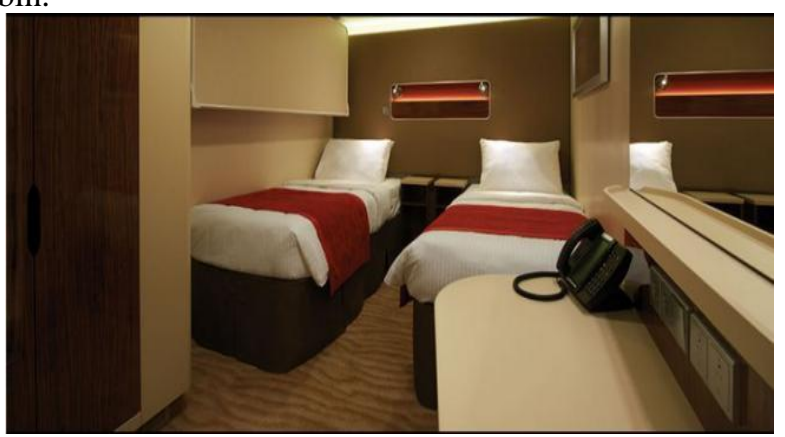

Figure 1 Interior view of inner cabin
The interior view of the inner cabin is shown in figure 1 .

Unit design of inner cabin:

Position: inside the hull and inside of the corridor are arranged side by side, without opening Windows to the outside. The position of the inner compartment on the ship is shown as follows :(take mariner for example)

Room: usually two standard rooms occupy a column distance, that is, one room for half column distance, generally about 2.6m;

Depth: according to the hull structure and basic cabin function requirements, generally $6 \sim 7 \mathrm{~m}$;

Net height: single layer, determined by the hull design, the internal net height is generally about $2.1 \mathrm{~m}$;

Functional composition: sleeping space, writing space, dressing space, living space, storage space, bathroom space;

Furniture and facilities: bed, bedside table, writing table, chair, TV set, sofa, tea table, closet, basin, sink, toilet, shower, etc.

\section{B. Oceanview cabin}

In some evaluation criteria, the size of the proportion of cabins with views of the outside is an important criterion to measure whether a cruise ship is luxurious. Oceanview rooms can have porthole windows, view windows or even french windows depending on the deck and hull design. Usually the sea view room is a little larger than the cabin room, the internal facilities are basically the same. The presence of windows brightens the oceanview room, allowing for a sense of not only the changing weather and changing times, but also the ocean views. In some evaluation criteria, the size of the proportion of cabins with views of the outside is an important criterion to measure whether a cruise ship is luxurious. Oceanview rooms can have porthole windows, view windows or even french windows depending on the deck and hull design. Usually the oceanview room is a little larger than the cabin room, the internal facilities are basically the same. The presence of windows brightens the oceanview room, allowing for a sense of not only the changing weather and changing times, but also the ocean views.

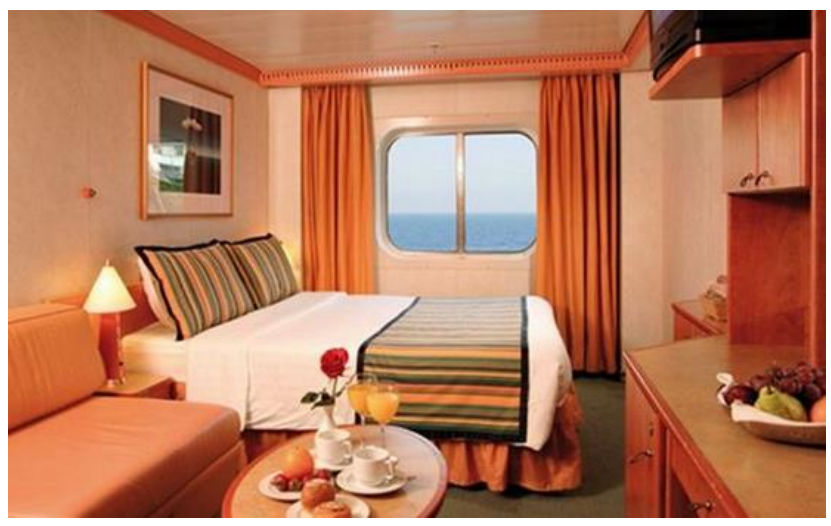

Figure 2 Interior view of Oceanview cabin

The interior view of the Oceanview cabin is shown in figure 2 .

Unit design of sea view house:

Location: the sea view rooms are located on both sides of the lower main deck of the ship.

Room: usually two standard rooms occupy a column distance, that is, one room for half column distance, generally about $2.6 \mathrm{~m}$;

Depth: according to the hull structure and basic function requirements of the cabin, generally about $6 \sim 7 \mathrm{~m}$; 
Net height: single layer, determined by the hull design, the internal net height is generally about $2.1 \mathrm{~m}$;

Functional composition: sleeping space, writing and dressing space, living space, storage space, toilet space;

Furniture and facilities: bed, bedside table, writing table, chair, TV set, chair, TV set, sofa, tea table, closet, basin, sink, toilet, shower.

\section{The balcony room}

As the name suggests, having a separate balcony is the most striking feature of this type of cabin. This kind of room compares seascape room price tall, indoor area is general and same big, on certain cruises, the plane of room of balcony room and seascape room, interior cabin is decorated somewhat distinction, the tourist can enjoy the scenery that changes ceaselessly on the balcony.

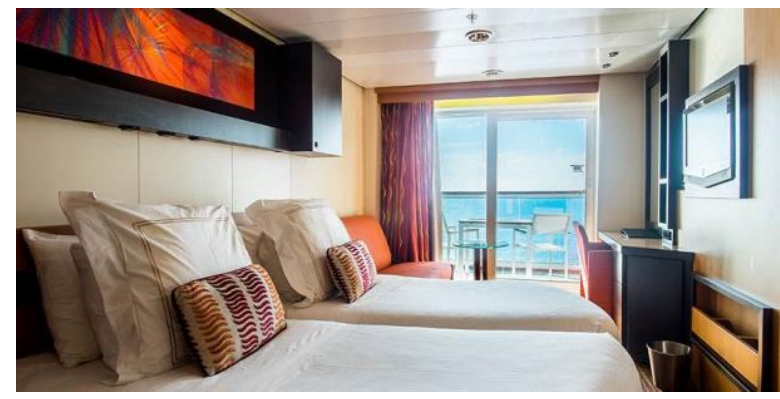

Figure 3 Interior view of the balcony room

The interior view of the balcony room is shown in figure 3 .

Position: the balcony room is the standard room type in cruise ship, it is the superlative class cabin type besides the flatlet. Balconies are located on the upper deck of the main hull, on the outer side of the hull.

Room: usually two standard rooms occupy a column distance, that is, one room for half column distance, generally about 2.6m; A few advanced balcony room can achieve 3/4 column to be apart from;

Depth: according to the hull structure and basic function requirements of the cabin, generally about $6 \sim 7 \mathrm{~m}$;

Net height: single layer, determined by the hull design, the internal net height is generally about $2.1 \mathrm{~m}$;

Functional composition: sleeping space, writing and dressing space, living space, storage space, toilet space;

Furniture and facilities: bed, bedside table, writing table, chair, TV set, chair, TV set, sofa, tea table, closet, basin, sink, toilet, shower.

\section{Suite}

The construction of a certain number of suites is the cruise to receive high-end guests need. A living space connecting one or more bedrooms constitutes a suite. There are many types of suites, such as mini suites, second suites, third suites, deluxe suites, presidential suites and so on. The quantity of flatlet and the proportion that occupy differ because of cruise line type, most cruise line has the flatlet configuration of $5 \%$ 10\% only, advanced luxurious cruise line offers the flatlet of $20 \%$ above, some even are flatlet entirely.

As the upgrade of flatlet, its space can increase ceaselessly, the function also can subdivide more, arrive from reception room small dining room, kitchen, study, make up, cloakroom, more and more resemble the residence on land. The presidential suite of modern luxury cruise ship is just like a luxury villa, which provides the most advanced equipment and exquisite luxury interior decoration in the contemporary, staying in it is one of the symbols of tourist status and rank.

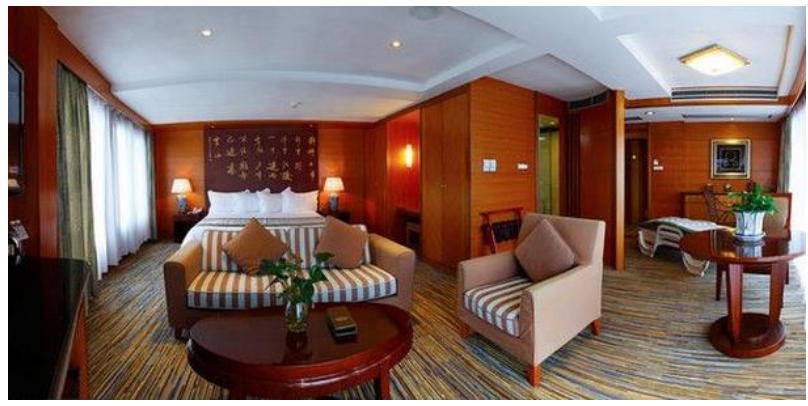

Figure 4 Interior view of the suite

The interior view of the suite is shown in figure 4.

Unit design of suite:

Location: suites are generally located at the bow and stern of cruise ships, the upper floor or the corner, or in the places where the hull structure provides shaped rooms. If the bow and stern are used to fall naturally, the balconies and balconies will be formed, where you can enjoy better scenery and better service. Usually by two balcony standard room combination but becomes, is located in the cruise ship bow stern place or the unusual shape corner office suite opens the room according to the design but decides. The depth and height of the suite will be adjusted according to the hull design.

Rooms: most of the standard rooms by the combination of two balcony rooms, located in the cruise at the bow and stern or corner suite rooms are determined according to the design.

Depth: according to the hull design;

Height: most suites are single rooms, some suites for the floor;

Functional composition: basic space -- sleeping space, writing and dressing space, living space, storage space, toilet space; Advanced space -- reception room, small dining room, kitchen, study, dressing room, cloakroom, hall, etc.;

Furniture and facilities: bed, bedside table, writing table, chair, TV set, chair, TV set, sofa, tea table, closet, basin, wash basin, toilet, shower, bathtub, stereo surround sound, bar, piano, table, etc.

\section{E. Barrier-free room}

Barrier-free design is ono of the cruise functionality in the design of a system, the sixty-sixth Session of the Maritime Safety Sommittee pointed out that must be considered with different degree of physical disability defect and normal activity ability decline the use of demand, is equipped with device can meet the special requirements of the service function and response, so it can convenient quickly mounted or evacuation ships, and ensure that their activities in the ship safety and convenient.

On cruise ship, 4 kinds of basic room can configure certain scale normally (about 1\% 2\%) barrier-free room. On ships with cabins, cabins suitable for wheelchair users shall be provided, and barrier-free cabins shall be located in places convenient for evacuation. A minimum of $140 \mathrm{~cm} 140 \mathrm{~cm}$ rotation space should be reserved in the bed or rest area. The bed should be $50 \mathrm{~cm}$ off the ground. The switch of the reading light should be above the bed surface to ensure that it can be touched on both the wheelchair and the bed. The electrical switch shall be in a convenient place, $90 \mathrm{~cm}$ above the ground. 
Doors should be pushed sideways or open outwards, unless there is sufficient space in the cabin to open inwards and allow the wheelchair to rotate freely, with a net width of at least $90 \mathrm{~cm}$. The cabin should also be equipped with call assistance equipment.

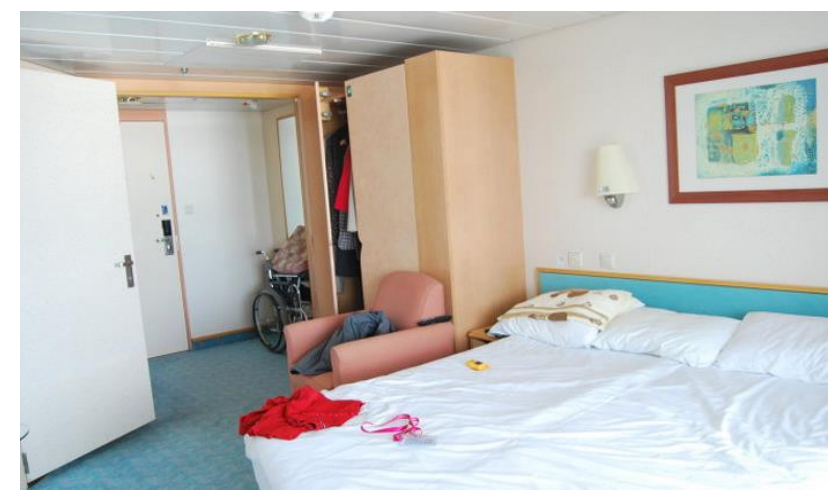

Figure 5 Interior view of the Barrier-free room

The interior view of the Barrier-free room is shown in figure 5 .

There should be $110 \mathrm{~cm} 90 \mathrm{~cm}$ barrier-free space in the toilet to make the wheelchair turn freely. The toilet should be installed at a height of $45 \sim 48 \mathrm{~cm}$ above the ground. On both sides of the toilet, there should be foldable or swinging grasping bars. Lavabo must not rise above ground $80 \mathrm{~cm}$, and fixed device should enough firm, so that the hand basin can serve as prop establishment. The mirror should be placed at a suitable height, with the lower edge not higher than $90 \mathrm{~cm}$ from the ground and the upper edge not lower than $190 \mathrm{~cm}$ from the ground. The washbasin should be $70 \sim 75 \mathrm{~cm}$ below the ground to ensure the free push of the wheelchair. Soap, towels, etc. should be placed $90 \sim 100 \mathrm{~cm}$ from the ground. The toilet should also be equipped with call assistance equipment.

The interior view of the Barrier-free room toilet is shown in figure 6 .

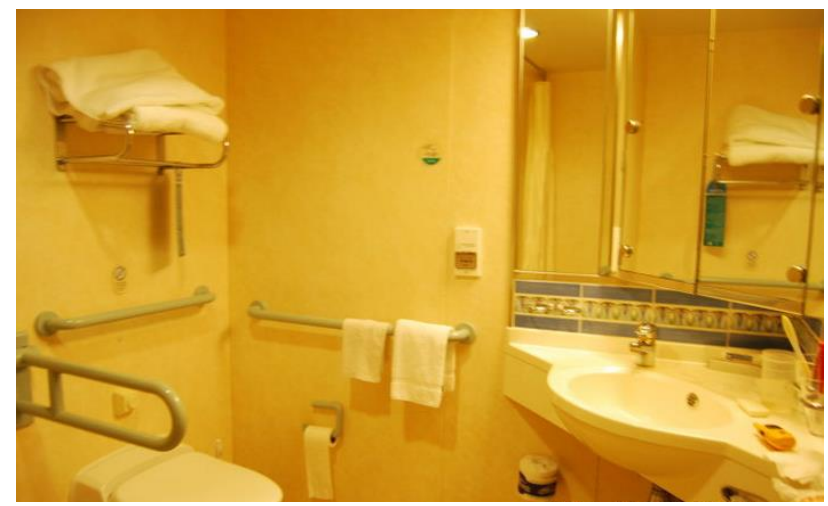

Figure 6 Interior view of the toilet

\section{Closing Remarks}

With the rapid development of modern cruise lines, more and more personalized and refreshing cabin types emerge, such as single cabin, loft cabin, wave cabin and so on. These rooms are basically developed from the four basic rooms, the general pattern remains unchanged, and new types are derived through design adjustment, so as to provide more choices for tourists with different needs.

\section{REFERENCES}

[1] Douglas Ward President. The Maritin Evaluations. Berlitz: The Complete Guide to Cruising\&Cruise Ship [M]. Insight Print Severices (Pte) Ltd., 2013.

Li Lanmei,Huang fei, Chen Mingming. Preliminary analysis on the construction characteristics of luxury cruise ships $[\mathrm{J}]$. Shipbuilding technology,2014,(02):10-13+26.

[3] Yang jie. Cruise ship operation practice [M]. Beijing: university of international business and economics press, 2012

[4] Zhang yue. Indoor ergonomics [M]. 2nd Ed. Beijing: China building industry press, 2005.

[5] The official royal Caribbean cruises website www.royalcaribbean.com 